\title{
Design of Web Based Information System Oriented to University Science Research Project
}

\author{
Xiao $\mathrm{CHEN}^{\mathrm{a}}$, Bo JIANG ${ }^{\mathrm{b},{ }^{,}, \text {Wei HAO }^{\mathrm{c}} \text {, Qi JIANG }}$ \\ State Grid Shaanxi Province Electric Power Company Training Center, No.180.Changlexi Road, \\ Xi'an, 710032, China \\ achenxiao0710@126.com, bijiangbo0333@163.com, chaowei0710@126.com, \\ djiangqi0316@126.com \\ *Corresponding author
}

Keywords: Research Project Management, C/S and B/S, SQL Server2005.

\begin{abstract}
With the increasing development of science and technology, for a university, the proportion of science research activities and research capacities is increasing gradually in assessing its overall strength. By means of information technology for managing the daily research work, integrating scientific research process, and providing real and effective decision-making basis, is an effective approach to enhance research management level. Moreover, it is also a general trend of today's science research management in universities. Giving concerns to the strategic development of the information management system, this article designed a band new mode of college scientific research management information system in order to improve the efficiency and quality of scientific research management, which could better cater the needs of college and researchers. The system has the functions such as person basic information management, project application management, project management, research product management, work count management, statistics management, and system setup, so that can satisfy the requirement of science research management department in universities. The contents of the study are summarized, elaborated the main work, points out the deficiencies of this paper, and the further work is prospected. The system for teachers, the department head, Department of science and technology management personnel in the treatment of scientific information provides convenient, promoted the process of scientific research information school, also has laid the technical foundation for the future system upgrade or to develop a more comprehensive scientific research management system.
\end{abstract}

\section{Introduction}

The further development of the national social economy, as well as the development of colleges and universities, the increase of scientific research investment in colleges and universities, for the university's scientific research project management put forward new challenges. At the same time with the continuous development of information technology and the country for the "Internet + " development of the promotion, should focus on the above-mentioned means used in scientific research management process, improve management efficiency and management level, reduce the project for the project, project information, project funding management difficulty. From the end of the 20 th century to the beginning of the 21 st century, the government has increased the financial support in the cause of higher education, through the implementation of the strategy of rejuvenating the country through science and education, "211 Project", "985 Project", "Educational Revitalization Action Plan" Education has made fruitful results, the university's scientific and technological work is also on the basis of this vigorous development. Under the background of this age, how to apply the scientific research management system becomes the subject of the relevant staff and researchers in colleges and universities, and how to apply the scientific research management system to the increasingly complicated and complicated scientific research task management. 


\section{The Necessity of Establishing Scientific Research Management System in Colleges and Universities}

For a comprehensive university, the subject of many categories, scientific research projects involved in the field of science is broader, the number is more. The use of computer management is the most scientific and most effective way, on the one hand can improve efficiency and quality of work, while facilitating the exchange of information between departments to achieve resource sharing. In the future, the development of scientific research management in colleges and universities must be based on computer software technology and network technology to form a comprehensive scientific research management system of information integration, so that the scientific research management work of colleges and universities can realize the modernization of information, digitization and specialization, So as to continuously promote the development of scientific research in colleges and universities. Therefore, with the support of modern information technology, relying on information talents to maximize the utility of information resources as the goal, to establish a set of "information sharing, decision support, online office" integrity "One-stop" technology project management service system is imperative.

\section{Analysis on the Current Situation of Establishing Scientific Research Management System in Colleges and Universities}

Scientific research is of vital importance to a comprehensive research university, and the level of research has become to measure the comprehensive strength of colleges and universities an important indicator, with the increasing commitment of scientific research in colleges and universities, scientific research projects, research funding and scientific research output increased year by year, but also on the management of university management departments put forward higher requirements. At present, colleges and universities for teaching and personnel aspects of information management has matured, the relevant management system has long been applied to the management of colleges and universities, and unified into the development and construction of the campus network, the operation is relatively stable. But for scientific research management, the general university research management department of the work is still in the semi-manual or even manual stage. The so-called information management is the use of ordinary office software for a simple record, there is no good use of management information systems for scientific research management, low efficiency. Although some colleges and universities have built a database for research information records, but mainly a record of scientific research project information and funding management, and in fact in the daily scientific research management work also need scientific research results classification management, including papers, patents, awards, identification, as well as research institutes and researchers data sharing, so as to achieve the purpose of management for scientific research services, in addition to the integration of data utilization and statistical analysis of the report can provide scientific research and development planning and decision-making basis. With the development of information technology, the continuous management of information systems, the use of network and database technology for scientific research management to help achieve data sharing, standardize scientific research data, reduce office expenses, and improve the management of information technology, Improve work efficiency and decision-making ability.

\section{The Establishment of Scientific Research Management System in Colleges and Universities Related Technology}

(1) ASP technology

ASP (Active Server Pages) is Microsoft's Web server-side development environment, use it to generate and run dynamic, interactive, high-performance Web server applications. ASP not only can carry out complex database operation, and the generated page has a strong interactive, users can easily control and manage data. Therefore, you can use ASP to create an interactive and efficient Web 
application.ASP technology is the biggest advantage of the full use of client / server model for division of labor, the server is responsible for interpreting the scripting language, and the client is full of screen display and input. But when the client every time the ASP page request, the server side must re-compile a compile, when the number of clients and requests increased, it will affect the efficiency of the server.

(2) C / S and B / S combined architecture model

Client / Server (client / server) structure, that is, C / S structure, is the 20th century, 90 years began a popular software architecture, the application system is divided into two parts: the front end of the client and the background server, the application processing is done by the client, the data access and transaction processing are borne by the server, the task needs to be configured without the client side and the server side. Browser / Server (browser / server) structure, that is, B / S structure, is the rise of the Internet technology, the C / S structure of a change or improved structure. The B / S model is formed by a three-tier structure, which further deepens the server side of the C / S model into an application server and one or more database servers. In this structure, the user interface can be completely through the browser achieve. Considering that both C / S and B / S modes have their own advantages in different application environments. C / S and B / S combined with the software to build the model, this construction mode is better than the simple C / S mode and B / S mode, can effectively improve the server's responsiveness, the system traffic increases, the system Will still have a faster response speed. Therefore, in the system design to consider the use of C / S and B / S mode combination of the basic idea is to provide Web-based online interactive features and special needs for the C / S mode based on efficient management functions. To achieve the general needs of the Internet as a platform, through the Web browser to obtain and update scientific research information, scientific research management staff to install the client software to efficiently complete the research information collection and statistics work objectives.

(3) SQL Server2005 database

SQL Server 2005 is a comprehensive database platform that provides enterprise-class data management with integrated business intelligence (BI) tools. The SQL Server 2005 database engine provides a more secure and reliable storage for relational and structured data that enables you to build and manage high-availability and high-performance data applications for your business. The SQL Server 2005 data platform provides the following benefits:

A. Take full advantage of data assets: In addition to providing a secure and reliable database for line of business and analytics applications, SQL Server 2005 enables users to access data from embedded data, such as reports, analytics, and data mining, from their data get more value.

B. Increased Productivity: With comprehensive business intelligence capabilities, and tools such as the familiar Microsoft Office system, SQL Server 2005 provides critical and timely business information to the organization's information workers to meet their specific needs. The goal of SQL Server 2005 is to extend business intelligence to all users within the organization and ultimately allow all levels of users within the organization to make better decisions based on their most valuable asset data.

C. Reduce IT complexity: SQL Server 2005 simplifies the development, deployment and management of business lines and analysis of the complexity of the application, it provides developers with a flexible development environment for database administrators to provide an integrated automated management tools.

D. Lower Total Cost of Ownership (TCO): Provides the industry's lowest planning, implementation and maintenance costs for product ease-of-use and deployment concerns and integrated tools, enabling database investments to be rewarded quickly.

Based on the above characteristics, the system will regard SQL Server 2005 as a back-end database. 


\section{Universities to Establish Scientific Research Management System to Achieve the Goal}

Through the construction of scientific research management system, we can realize the network management of scientific research work, form a dynamic scientific research data center and scientific research management communication platform, comprehensive, real-time and accurately provide relevant scientific research information of the school, serve the university scientific research staff, Scientific research management decision-making, so as to carry out the work of scientific research personnel to provide great convenience. In view of this, through the understanding of scientific research management work, look forward to the scientific research management system objectives are as follows:

(1) all-round scientific research management, comprehensive collection, processing and storage can reflect the level of scientific research and scientific research status of scientific research data.

(2) to assist the departments responsible for scientific research or scientific research management of the unit scientific research work. So that all units can grasp the direction of the unit's scientific research and status.

(3) accurate and efficient statistical functions, can be a variety of data analysis, when needed, can form an intuitive map or table, so as to provide leaders with various types of scientific research information for scientific decision support.

(4) comprehensive, real-time, accurate provision of school research information. (Including projects, achievements, awards, academic activities, assessment, etc.) can be displayed on the system, and can be retrieved and modified, etc., after the audit by the scientific research manager, the research information (including projects, achievements, awards, academic activities, assessment, etc.) The And by setting permissions, you can ensure data security, do not have to worry about being malicious modification.

(5) to achieve a comprehensive network of office, engaged in scientific research activities for the school staff, for researchers to provide a management of personal scientific research activities of the network space, to achieve personal scientific research declaration, the results of registration, query network, save time and work effectiveness.

\section{The Main Function of Establishing Scientific Research Management System in Colleges and Universities}

According to the school's research activities of the business process, the system is divided into the following main functional modules: Reporting management, project management, results management, statistical report management, workload calculation, system maintenance. And for different users of the system to assign different permissions to provide different work platforms, show different functions.

(1) reporting management

Researchers to declare the project in the plan issued units after the establishment of the project, issued by the unit issued by the project approved approval, The technology department establishes the relevant project information according to the approval document, after the establishment of the relevant project information, the original project applicant to become the project leader, the person in charge of the project is required to fill in the basic information such as the name of the project team, the schedule, the budget and other information, and upload the project contract as an attachment, the Science and Technology Department regulates the progress of the project in line with the planned progress of the project leader.

Applicant functional description: The project applicant (the researcher) shall fill in the basic information of the declared item within the time limit for the declaration, and upload the application materials (the document is a unified document of the Science and Technology Department) and submit the project.

College (department) person in charge (research secretary) function description: The person in charge of the college (department) shall examine the project submission materials submitted by the 
college (department) within the project declaration period, if there is any change, return to the project applicant to modify, after passing the audit opinion, and give a conclusion. Continue to submit to the Science and Technology Department.

(2) project management

Researchers to declare the project in the plan issued units after the establishment of the project, issued by the unit issued by the project approval, The Technology Department establishes the relevant project information according to the approval document, after the establishment of the relevant project information, the original project applicant to become the project leader, The project leader shall fill in the basic information such as the name of the project team, the schedule progress, the budget table and so on, and upload the project contract as an attachment. The Science and Technology Department regulates the progress of the project in line with the planned progress of the project leader.

Technology Department Functional Description: The Science and Technology Department is responsible for establishing the basic information of the project according to the project approval issued by the planning unit. After the project, the project leader to submit the budget, income and expenditure, the progress of the project to fill the audit opinion.

Responsible functional requirements: Project leader to declare the project in the Science and Technology Department after the project, The project leader is required to submit project member information, project research progress information, budget information, and upload Word or Excel documents. After the project is completed, the project leader will need to submit the project report.

(3) scientific research management

Researchers to declare their own scientific research information (including: papers, writings, patents, achievements, etc.), The Technology Department according to the results of scientific research personnel to fill out the results of information, generate scientific research results, save the storage.

Researcher Functional Description: Researchers fill in personal scientific research information (research results include: papers, works, patents, achievements, etc.), submitted by the Science and Technology Department is responsible for review.

(4) workload statistics

The Science and Technology Department can carry out the calculation of the various workloads of the individual, the college (department) in different time periods, the different types of scientific research projects, the results and so on, including the calculation of the scientific research equivalent and the calculation of the scientific research reward.

Science and Technology Department Functional requirements: The research office can carry out the operation of the statistics of the researcher's work, the statistics of the college (department) workload, the report generation processing and so on.

(5) statistical report management

This can be a total of multi-faceted, multi-angle search, generate all kinds of statistical reports. According to the project leader (participants), the project title time, discipline, the type of results (papers, works, patents, results) statistics and generate reports.

Functional Requirements: This function includes research project statistics and report generation, project budget statistics and report generation, achievement statistics and report generation, cross comprehensive statistics and report generation; and query and generate statistical reports are different for different users of different permissions.

(6) system management

This is able to the entire system of users, system parameters, dictionary maintenance and modification.

Functional Requirements: Features include user rights management, user role management, user information management, system parameter management, dictionary management. 


\begin{abstract}
Summary
China is vigorously promoting the information construction, more and more colleges and universities have developed scientific research management system, strengthen the construction of digital campus, Which shows that China's education information technology has achieved good results. However, with the development of Internet technology, research management system based on the network technology will become the future of university research management one of the important tools. The discussion of the scientific research management system makes full use of the perfect network, facilities and rich network resources, using C / S and B / S based on the system architecture, so that the school's scientific research management staff to scientific and orderly management of various scientific research work, on the one hand it reduces the scientific research management of the complex labor, on the other hand to facilitate the daily work of teaching and research personnel. This is a useful attempt to information management of scientific research management, but also a scientific and technological management of the University of a reform and innovation.
\end{abstract}

\title{
References
}

[1] Xu Xiaole. On the Scientific Research Management of Universities in the New Situation[J]. Science and Technology Innovation Herald,2011(35):206-207.

[2] Liao Ping, Zhang Jian.Optimal Design of Scientific Research Management Information System in Colleges and Universities[J].Modern intelligence,2006(09):35-38+41.

[3] Zhou Jing.Research and Realization of University 's Scientific Research Management Information System Based on[J]. Software Guide,2011(09):104-105.

[4] Sun Qiang, Zhang Shuangjie.Analysis and Development of University - based Scientific Research Management System Based on[J]. Fujian Computer,2008(12):119-120. 